\title{
Acúmulo de forragem em pastos de Tifton 85 adubados com nitrogênio e manejados sob lotação contínua ${ }^{1}$
}

\section{Biomass of the forage in Tifton 85 pastures fertilized with nitrogen and managed under continuous stocking}

\author{
Andréia Luciane Moreira ${ }^{2 *}$; Jailson Lara Fagundes ${ }^{3}$; Eidi Yoshihara²; \\ Alfredo Acosta Backes ${ }^{3}$; Leandro Teixeira Barbosa ${ }^{3}$; \\ Luiz Fernando Ganassali de Oliveira Júnior ${ }^{3}$; Gladston Rafael de Arruda Santos ${ }^{3}$; \\ Monica Alixandrina da Silva Arruda Santos ${ }^{4}$
}

\begin{abstract}
Resumo
O presente ensaio foi realizado na Unidade de Pesquisa e Desenvolvimento de Adamantina, SP, da Agência Paulista de Tecnologia dos Agronegócios (APTA) - Polo da Alta Paulista, com objetivo de avaliar o efeito da adubação nitrogenada na composição morfológica, densidade populacional de perfilhos, índice de área foliar, interceptação luminosa e acúmulo de forragem em pastos de Tifton 85 submetidos ao regime de lotação contínua. Os tratamentos corresponderam a três doses de nitrogênio e o controle $(0,100,200$ e $400 \mathrm{~kg} / \mathrm{ha} / \mathrm{ano}$ de $\mathrm{N})$, dispostos em delineamento experimental de blocos casualizados com quatro repetições. Não foi constatado efeito da época de avaliação na densidade populacional de perfilhos vegetativo, morto e total de Tifton 85 em lotação continua com carga variável. Os parâmetros avaliados nos pastos de Cynodon cv. Tifton 85 sofrem influência da época de avaliação e das doses de nitrogênio com efeito marcante na composição morfológica do pasto, índice de área foliar e interceptação luminosa que são determinantes no acúmulo de forragem. O capim Tifton 85 alcançou as condições necessárias para atingir a taxa de crescimento da cultura máxima quando manejado sob lotação continua mantendo-se o pasto a $15 \mathrm{~cm}$ de altura.
\end{abstract}

Palavras-chave: Características estruturais, cynodon spp., ovinos, pastejo

\begin{abstract}
The present study, carried out at the Division for Research and Development of Adamantina, SP/Brazil, at Agência Paulista de Tecnologia dos Agronegócios (APTA) - Polo da Alta Paulista, aimed to evaluate the effect of nitrogen fertilization on the morphological composition, tiller density, leaf area index, light interception and forage accumulation of Tifton 85 pastures subjected to continuous grazing. Treatments corresponded to three nitrogen and control doses $(0,100,200$ and $400 \mathrm{~kg} \mathrm{~N} / \mathrm{ha} /$ year), arranged in a randomized block design with four replications. No effect of time of evaluation was verified on the vegetative, dead and total tiller densities of Tifton 85 under continuous grazing with variable stocking rate. The pastures of Cynodon cv. Tifton 85 were affected by the time of evaluation and nitrogen doses,
\end{abstract}

\footnotetext{
${ }^{1}$ Pesquisa financiada pela Fundação de Amparo de Pesquisa do Estado de São Paulo, FAPESP.

2 Pesquisadores Científicos, Polo Alta Sorocabana/APTA/SAA, Presidente Prudente, SP. E-mail: aluciane@apta.sp.gov.br; eidi@ apta.sp.gov.br

3 Profs. Drs,. Universidade Federal de Sergipe, UFS, São Cristóvão, SE. E-mail: ratinhojlf@yahoo.com.br; alfredoaab_67@yahoo. com.br; leandro35441@yahoo.com.br; lfg.ufs@gmail.com; gladstonrafael@ufs.br

${ }^{4}$ Prof $^{a}$, Instituto Federal de Educação, Ciência e Tecnologia de Sergipe, São Cristovão, SE. E-mail: monica.alixandrina@ifs.edu.br

* Autor para correspondência
} 
with marked effect on the pasture morphological composition, leaf area index and light interception, which are determinant to forage accumulation. Tifton 85 grass reached the necessary conditions to achieve the maximum growth rate of the culture when managed under continuous grazing keeping the pasture at a height of $15 \mathrm{~cm}$.

Key words: Cynodon spp., grazing, sheep, structural characteristics

\section{Introdução}

A baixa produtividade de áreas de pastagens no Brasil é uma das principais causas da baixa rentabilidade e competitividade dos sistemas de produção animal em relação a outros sistemas agrícolas. Isso se deve, em parte, à falta de conhecimento dos limites de utilização das plantas forrageiras nos ambientes. A compreensão do processo de acúmulo de forragem em um pasto, aliado às diferentes respostas ao processo de pastejo determina o conhecimento das respostas das gramíneas tropicais ao manejo a que são impostas.

Segundo Da Silva (2004), em virtude do grande potencial de produção das gramíneas tropicais, ocorre subutilização dessas plantas nos sistemas de produção. Essa constatação é agravada pelo fato de, no manejo, de modo geral, não se considerar a importância da eficiência de utilização da forragem produzida. A manipulação do processo de desfolhação por ajustes e combinações entre frequência e intensidade de corte ou pastejo podem gerar respostas diferenciadas em acúmulo e valor nutritivo da forragem produzida, promovendo variações em área foliar a partir de alterações nos padrões demográficos de perfilhamento das plantas forrageiras (DIFANTE et al., 2008).

Práticas como calagem, manejo do pastejo, irrigação e adubação de pastagens, particularmente a nitrogenada, proporcionam aumentos em produção de matéria seca. Portanto a resposta das plantas forrageiras à adubação nitrogenada depende, principalmente, da espécie utilizada, da forma de utilização da forragem, do tipo de solo, do teor de matéria orgânica e das condições climáticas. Desta forma a utilização da fertilização nitrogenada tem proporcionado mudanças na produção de forragem devido a alterações nas características morfológicas e estruturais das plantas forrageiras, influenciando a produção de matéria seca (FAGUNDES et al., 2006a, 2006b).

Contudo, existe carência de informações sobre o padrão de resposta desta forrageira tropical manejada em sistema de produção animal com lotação continua, em relvados monitorados, submetidos à adubação nitrogenada (FAGUNDES et al., 2005). Assim, conduziu-se este trabalho com o objetivo de avaliar o efeito da adubação nitrogenada na composição morfológica, densidade populacional de perfilhos, índice de área foliar, interceptação luminosa e acúmulo de forragem em pastos de Tifton 85 submetidos ao regime de lotação contínua.

\section{Material e Métodos}

O ensaio foi conduzido no Pólo de Pesquisa e Desenvolvimento da Agência Paulista de Tecnologia dos Agronegócios (APTA) - Polo da Alta Paulista pertencente à Secretaria de Agricultura e Abastecimento - SP. A área experimental está situada no município de Adamantina, SP, sob as coordenadas geográficas de $21^{\circ} 40^{\prime} \mathrm{S}$ de latitude e $51^{\circ} 08^{\prime} \mathrm{W}$ de longitude e 415 metros de altitude, o clima da região é do tipo Cwa, com estação chuvosa e quente no verão e inverno seco, segundo a classificação de Köppen (BRASIL, 1960). O período experimental compreendeu-se entre 01/12/2008 a 30/04/2009.

O experimento foi instalado em solo classificado como argissolo vermelho-amarelo, eutrófico, A moderado, textura arenosa/média e topografia ondulada (EMBRAPA, 2009), cuja análise do solo 
revelou os seguinte resultados: $\mathrm{pH}\left(\mathrm{CaCl}_{2}\right)=5,2$; $\mathrm{MO}\left(\mathrm{g} / \mathrm{kg}^{1}\right)=11,0 ; \mathrm{P}\left(\mathrm{mg} / \mathrm{dm}^{3}\right)=16,0 ; \mathrm{K}\left(\mathrm{cmol}_{\mathrm{c}}\right)$ $=2,3 ; \mathrm{Ca}\left(\mathrm{cmol}_{\mathrm{c}}\right)=16,0 ; \mathrm{Mg}\left(\mathrm{cmol}_{\mathrm{c}}\right)=8,0 ; \mathrm{H}+\mathrm{Al}$ $\left(\mathrm{cmol}_{\mathrm{c}}\right)=15,0 ; \mathrm{SB}\left(\mathrm{cmol}_{\mathrm{c}}\right)=24,5 ; \mathrm{T}\left(\mathrm{cmol}_{\mathrm{c}}\right)=$
41,0 e $\mathrm{V}(\%)=63,0$. Os elementos meteorológicos utilizados foram obtidos no Posto Meteorológico da APTA/ Polo da Alta Paulista conforme pode ser observado na Tabela 1.

Tabela 1. Precipitação pluvial e temperaturas mensais do ar (máxima, mínima e média) durante o período experimental.

\begin{tabular}{lcccc}
\hline \multirow{2}{*}{ Mês } & $\begin{array}{c}\text { Precipitação } \\
(\mathrm{mm})\end{array}$ & Máxima & Memperatura $\left({ }^{\circ} \mathrm{C}\right)$ & \\
\cline { 3 - 5 } & 45,4 & 31,7 & 18,9 & Média \\
\hline Novembro/08 & 143,0 & 33,4 & 20,2 & 25,4 \\
Dezembro/08 & 364,0 & 30,1 & 20,2 & 26,8 \\
Janeiro/09 & 78,4 & 31,5 & 20,8 & 25,2 \\
Fevereiro/09 & 110,4 & 31,6 & 19,9 & 26,2 \\
Março/09 & 1,8 & 31,1 & 17,5 & 25,7 \\
Abril/09 & & & & 24,3 \\
\hline
\end{tabular}

Fonte: Arquivos do Posto Meteorológico da APTA - Polo da Alta Paulista (2009). Elaboração dos autores.

Os tratamentos consistiram de três doses de nitrogênio e o controle ou $0,100,200$ e $400 \mathrm{~kg} /$ ha/ano. Utilizou-se a uréia como fonte de adubo nitrogenado os quais foram distribuídos em três aplicações, 01 de dezembro de 2008, 08 de janeiro e 03 de fevereiro de 2009. Adotou-se o delineamento em blocos casualizados, com quatro repetições.

As unidades experimentais consistiram de 16 piquetes com áreas variando de 300 a $500 \mathrm{~m}^{2}$, áreas estas que se apresentavam de tamanhos inversamente à dose de nitrogênio aplicada, de modo a permitir a manutenção de taxa de lotação mais uniforme em todos os piquetes. Foram utilizados ovinos da raça Santa Inês como animais "testers" e animais mestiços da raça Santa Inês como "reguladores de carga animal".

A espécie forrageira utilizada foi o capim Cynodon spp. cv. Tifton 85. Em decorrência dos resultados da análise de solo, realizou-se a calagem e a adubação, conforme Lima e Vilela (2005), a qual ocorreu no ano agrícola de 2007/2008. A calagem foi realizada de forma a elevar a saturação de bases a $70 \%$, e a adubação de base foi constituída de 150 $\mathrm{kg} / \mathrm{ha}^{1}$ na formulação 3-36-18, aplicados no sulco de plantio, no ano agrícola de 2008/2009. Não foi realizada adubação de manutenção com Fósforo e Potássio.

A prática de calagem da área experimental foi realizada no dia 01/03/2007, a adubação e plantio das mudas ocorreram no dia 06/11/2007. Antes do início do experimento procedeu-se roçagem do pasto para uniformização da altura média do relvado a $15 \mathrm{~cm}(15 / 11 / 2008)$, iniciando-se o período de adaptação dos ovinos.

Os piquetes experimentais de Tifton 85 foram manejados sob lotação contínua, com taxa de lotação variável, no período experimental de 01/12/2008 a $30 / 04 / 2009$, sendo que a altura média da pastagem foi mantida em torno de $15 \mathrm{~cm}$, pela adição ou retirada dos animais reguladores ("put and take"). A altura do pasto foi monitorada semanalmente por meio de 40 medidas, realizadas ao acaso em cada piquete utilizando-se uma régua. Os animais foram colocados ou removidos dos piquetes quando a altura apresentava acima ou abaixo da desejada, respectivamente, utilizando-se ovinos da raça Santa Inês.

Para avaliação da composição morfológica do pasto foram colhidas três amostras de forragem 
ao nível do solo utilizando um quadrado $\left(0,16 \mathrm{~m}^{2}\right)$ por unidade experimental em cada amostragem. As amostras de forragem colhidas foram subamostradas e fracionadas em folhas (lâminas foliares verdes), colmos verdes (colmo + bainha foliar) e material morto (perfilhos e folhas mortas), pesadas e posteriormente secas e pesadas. Após a pesagem dos componentes folha, colmo e material morto na massa seca total de cada amostra colhida, foi estimado a massa de cada um dos componentes no dossel forrageiro.

$\mathrm{Na}$ avaliação da densidade populacional de perfilhos utilizou-se a unidade de amostragem representada por um anel de cano plástico (PVC) de $15 \mathrm{~cm}$ de diâmetro $\left(0,0165 \mathrm{~m}^{2}\right)$, sendo que, em cada unidade experimental realizou-se a amostragem de duas áreas do pasto, procedendo-se a contagem do número total de perfilhos basilares vegetativos e mortos. Para o número de perfilhos totais realizouse a soma dos perfilhos vegetativos e mortos.

Nas avaliações de interceptação luminosa (IL) e do índice de área foliar (IAF) do relvado utilizouse o analisador de dossel SUNSCAN: Sistema de Análise da Cobertura Vegetal (Delta T, Cambridge, Inglaterra). Para avaliar o IAF e a IL procedeu-se a medida em 10 pontos do relvado realizada abaixo e acima do dossel forrageiro, escolhidos de forma aleatória em cada unidade experimental, compondo o resultado médio de IAF e IL para cada unidade experimental.

$\mathrm{O}$ acúmulo de forragem foi medido dentro de gaiolas de exclusão, três por parcela, com área de 1 $\mathrm{m}^{2}$ cada com um intervalo de três semanas entre as amostragens, que eram alocadas em novos pontos representativos do pasto a cada nova avaliação do acúmulo de forragem, segundo Davies (1993).

Durante o período experimental foram realizadas cinco avaliações, Dezembro (01 a 31/12/08), Janeiro (01 a 31/01/09), Fevereiro (01 a 28/02/09), Março (01 a 31/03/09) e Abril (01 a 30/04/09).

Os dados foram analisados conforme medidas repetidas no tempo, pelo procedimento MIXED do SAS (1990). Os efeitos de dose de $\mathrm{N}$ e época do ano, e de suas interações, foram considerados fixos, e o efeito de blocos foi considerado aleatório (LITTELL; PENDERGAST; NATARAJAN, 2000). Após a análise de variância, nos tratamentos quantitativos que não foi constatado interação, foram submetidos à análise de regressão, já os tratamentos qualitativos foram submetidos ao teste Tukey, a 5\% de significância.

\section{Resultados e Discussão}

Não houve efeito significativo da interação doses de nitrogênio e época de avaliação na composição morfológica do pasto de Tifton 85 ficando os efeitos restritos a doses de nitrogênio e épocas de avaliação. A adubação nitrogenada não influenciou a porcentagem de folha do Tifton 85 , apresentando respectivamente valores de $28,4 \%$ de folhas presente no dossel forrageiro, restringindo o efeito a épocas de avaliação. No entanto a porcentagem de colmo e material morto foram influenciados pela época de avaliação (Tabela 2) e adubação nitrogenada (Figura 1).

Tabela 2. Composição morfológica dos pastos (\%) de Tifton 85 em diferentes épocas de avaliação.

\begin{tabular}{lcccccc}
\hline Variáveis & Dezembro & Janeiro & Fevereiro & Março & Abril & Significância \\
\hline Colmo & $44,2 \mathrm{BC}$ & $48,9 \mathrm{~A}$ & $45,3 \mathrm{~B}$ & $44,5 \mathrm{BC}$ & $42,0 \mathrm{C}$ & 0,0001 \\
Folha & $31,5 \mathrm{~A}$ & $26,6 \mathrm{C}$ & $27,2 \mathrm{BC}$ & $29,7 \mathrm{AB}$ & $27,8 \mathrm{BC}$ & 0,0001 \\
Material Morto & $24,4 \mathrm{C}$ & $24,5 \mathrm{C}$ & $27,4 \mathrm{~A}$ & $25,8 \mathrm{BC}$ & $30,2 \mathrm{~A}$ & 0,0001 \\
\hline
\end{tabular}

Médias seguidas de mesma letra, na linha, não diferem entre si $(\mathrm{P}>0,05)$ pelo Teste de Tukey.

Fonte: Elaboração dos autores. 
De forma geral, a composição morfológica dos pastos foi bastante consistente durante os meses de avaliação. Observa-se que os pastos foram compostos principalmente por colmo, seguido de folhas e material morto, concordando com os resultados relatados por Fagundes et al. (1999). Outro fator relevante é que com o passar dos meses constata-se aumento no percentual de material morto, devido principalmente a morte de folhas e perfilhos no dossel forrageiro (Tabela 2).

Figura 1. Porcentagem de colmo e material morto de Tifton 85 submetido ao pastejo em função das doses de nitrogênio. **Significativo a $5 \%$ pelo teste de Tukey.
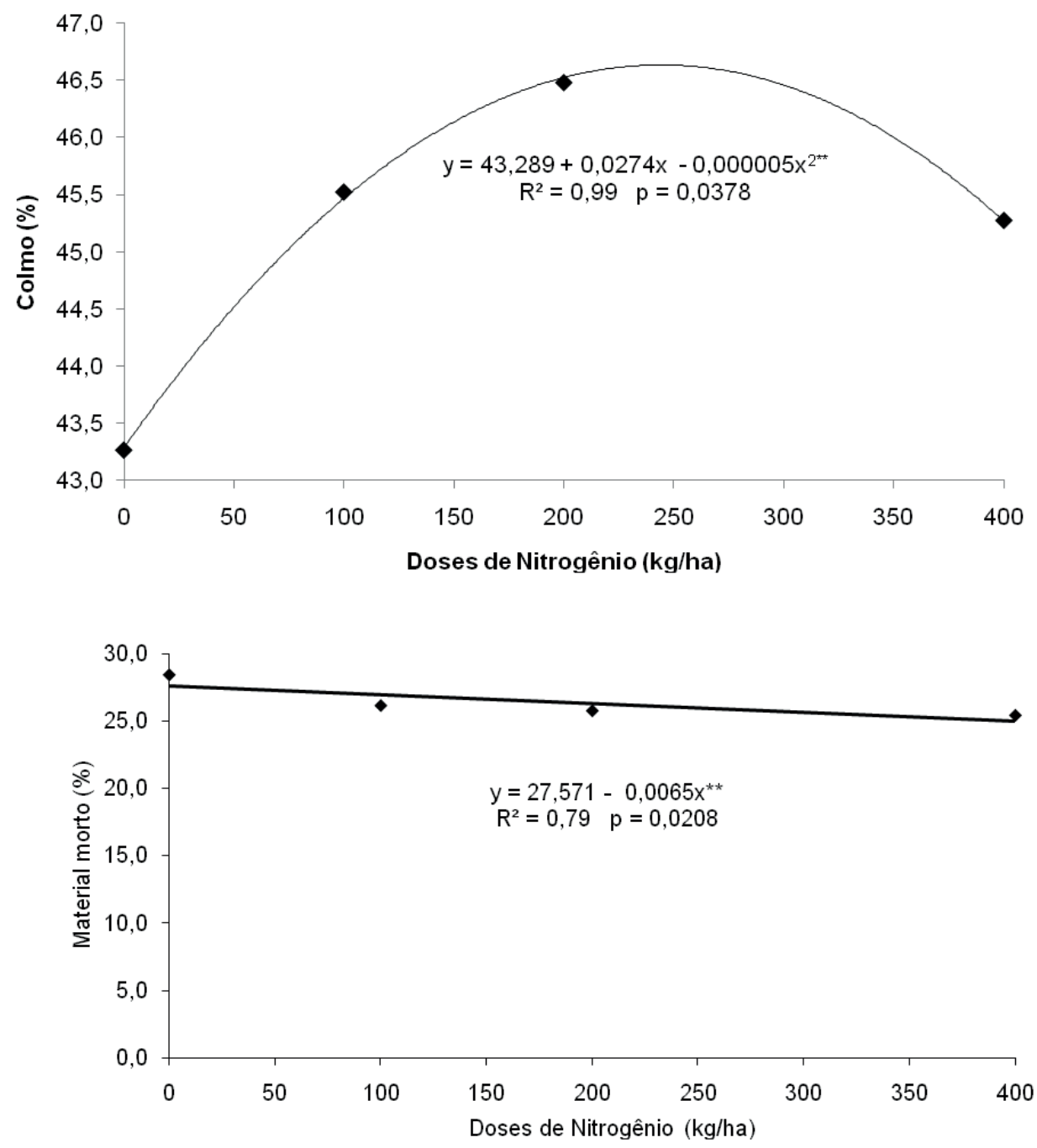

Fonte: Elaboração dos autores.

Pode-se constatar que os pastos apresentaram incremento na porcentagem de colmo e material morto com as doses de nitrogênio e ajustaram-se ao modelo quadrático e linear respectivamente (Figura 1). Possivelmente, com a adição do nitrogênio no pasto ocorreu estimulo no crescimento das folhas e colmos, que em consequência da manutenção da altura do pasto a $15 \mathrm{~cm}$ em todos os tratamentos permitiu que uma maior quantidade de folha fosse consumida, e assim alterando os componentes 
morfológicos que foram mantidos no dossel.

Carnevalli e Da Silva (1999), constataram que os valores porcentuais de folha para o capim 'Coastcross' foram mais elevados quando os fatores de crescimento não eram limitantes reduzindo a partir daí quando a planta perdeu sua capacidade de reposição rápida de folhas, por causa da queda de temperatura e umidade. No presente estudo os valores médios de folhas apresentaram variação na faixa de 26,6 a 31,5 \% (Tabela 2) similares aos apresentados por Fagundes et al. (1999). Esta menor variação pode ser atribuída a curta duração do período de avaliação (cinco meses) e ao método de pastejo empregado neste estudo.

Os valores porcentuais de folha e colmo no pasto praticamente tiveram pouca alteração à medida que avançou o período experimental. Este comportamento pode ser explicado pela manutenção da altura do pasto em condições similares (altura média de $15 \mathrm{~cm}$ ) ao longo dos meses de dezembro a abril (Tabela 2). Os valores porcentuais de colmo apresentaram pequena variação, na faixa de 42,0 a 48,9\%, enquanto que Carnevalli e Da Silva (1999) relatam valores porcentuais de colmo para o capim Coastcross variando entre 22,1 e $56,2 \%$. Os valores obtidos para material morto no pasto podem ser considerados baixos e poderiam ser um indício de alta utilização da forragem produzida. No entanto, uma análise mais cuidadosa dos fatos permite inferir que isso pode não ser verdade, uma vez que a forragem sendo utilizada seria aquela consumida acima da altura de pastejo especificada, ficando a biomassa abaixo desta com acesso bastante restrito ao animal. Neste caso os resultados estariam apontando apenas para uma mudança na estrutura dos pastos apresentados aos animais.

Não foi constatado interação doses de nitrogênio e épocas de avaliação para o índice de área foliar (IAF) e interceptação luminosa (IL) sendo limitados aos fatores isolados de doses de $\mathrm{N}$ e época de avaliação.

O IAF e a IL variou em função das doses de nitrogênio, ajustando-se, respectivamente, ao modelo quadrático e linear (Figuras 2a e 2b), e da época de avaliação, com menores valores de IAF ocorrendo em fevereiro, março e abril (Tabela 3). O aumento do IAF com as doses de nitrogênio estão em consonância com os resultados observados por Fagundes et al. (2006a) que encontraram valores variando 1,86 , no inverno a 3,99 , no verão.

Tabela 3. Índice de área foliar (IAF) e interceptação luminosa (IL) em pasto de Tifton 85 submetidos a adubação nitrogenada.

\begin{tabular}{lcccccc}
\hline Variáveis & Dezembro & Janeiro & Fevereiro & Março & Abril & Significância \\
\hline IL $(\%)$ & $96,3 \mathrm{AB}$ & $96,4 \mathrm{~A}$ & $96,6 \mathrm{~A}$ & $95,6 \mathrm{BC}$ & $95,1 \mathrm{C}$ & 0,0001 \\
IAF & $3,09 \mathrm{AB}$ & $3,52 \mathrm{~A}$ & $2,93 \mathrm{~B}$ & $2,99 \mathrm{~B}$ & $2,80 \mathrm{~B}$ & 0,0025 \\
\hline
\end{tabular}

Médias seguidas de mesma letra, na linha, não diferem entre si $(\mathrm{P}>0,05)$ pelo Teste de Tukey.

Fonte: Elaboração dos autores.

Nota-se que ocorreu aumento no IAF e na IL nos tratamentos que receberam adubação nitrogenada. Possivelmente este fato deve estar correlacionado a melhora no status nutricional das plantas de Tifton 85. Segundo Fagundes et al. (2006a) a explicação para tal fato deve-se ao efeito do nitrogênio no número de folhas vivas por perfilhos, comprimento final das folhas, taxa de alongamento foliar e densidade populacional de perfilhos.

Os menores valores de IL foram verificados na ausência da adubação nitrogenada (Figura 2a) sendo explicado pelos baixos valores de IAF (Figura 2b). Cabe salientar que mesmo na ausência da adubação nitrogenada as plantas de Tifton 85 conseguiram 
interceptar 95\% da luz (Figura 2b) garantindo da luz incidente a cultura estaria próxima de um valores para o IAF crítico. É fato amplamente valor máximo na taxa de crescimento (DA SILVA; reconhecido que, quando o pasto intercepta 95\% CORSI, 2003).

Figura 2. Índice de área foliar e Interceptação Luminosa em pastos de Tifton 85 em função de doses de nitrogênio. *Significativo a $5 \%$ pelo teste de Tukey.
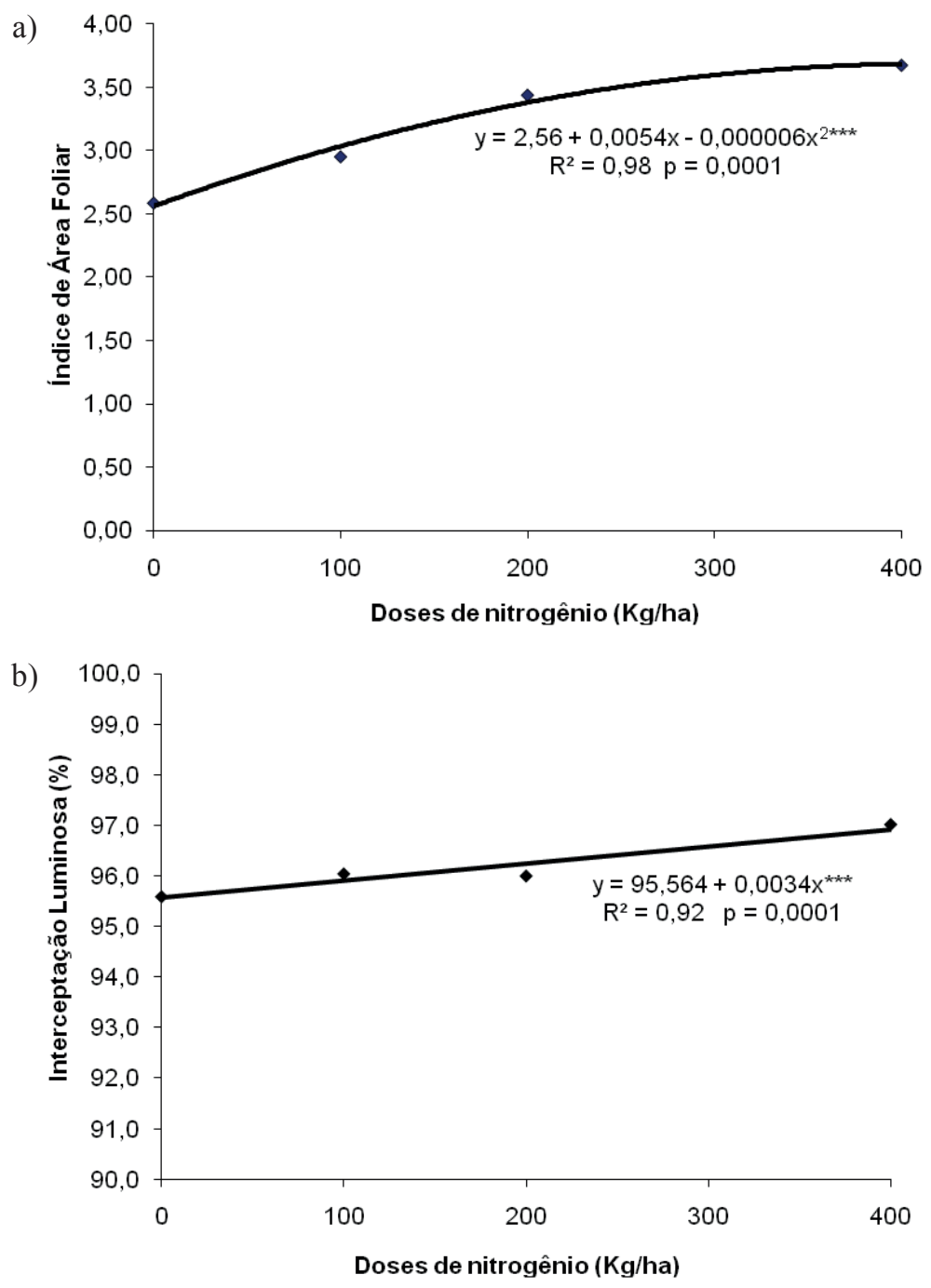

Fonte: Elaboração dos autores.

Não foi constatado efeito da época de avaliação na densidade populacional de perfilhos vegetativo, morto e total (Tabela 4), o mesmo deve-se ao fato da comunidade de plantas sob pastejo procuraremse ajustar às diferentes condições e intensidades de desfolha (MATTHEW et al., 1999), assim, como no estudo foi mantido sob uma mesma intensidade de desfolha, o mesmo não ocorreu modificações nas respectivas densidade de perfilhos. 
Tabela 4. Densidade populacional de perfilhos $\left(\right.$ perfilho $\left./ \mathrm{m}^{2}\right)$ vegetativos, mortos e totais em pasto de Tifton 85 submetidos ao pastejo e avaliado em diferentes épocas.

\begin{tabular}{lcccccc}
\hline Perfilhos & Dezembro & Janeiro & Fevereiro & Março & Abril & Significância \\
\hline Vegetativos & 2340 & 2440 & 2329 & 2265 & 2134 & 0,4789 \\
Mortos & 366 & 275 & 306 & 338 & 330 & 0,4622 \\
Totais & 2706 & 2715 & 2635 & 2603 & 2434 & 0,3958 \\
\hline
\end{tabular}

Médias seguidas de mesma letra, na linha, não diferem entre si $(\mathrm{P}>0,05)$ pelo teste de Tukey.

Fonte: Elaboração dos autores.

Em geral, os valores médios da densidade populacional de perfilhos vegetativos foi de 2134 a 2440 perfilhos $/ \mathrm{m}^{2}$ (Tabela 4), respectivamente, são menores que os relatados por Carvalho et al. (2000) para a mesma espécie sob pastejo, que constataram variação de 8620 a 13050 perfilhos/ $\mathrm{m}^{2}$. Esta diferença deve-se ao fato de que Carvalho et al. (2000) computou todos os perfilhos presentes no pasto, perfilhos basais e aéreos, e no presente estudo foram computados somente os perfilhos basilares.
Constatou-se efeito de adubação nitrogenada na densidade de perfilhos vegetativos e totais em Tifton 85 sob pastejo apresentando resposta positiva as doses de nitrogênio (Figura 3) o que provavelmente decorreu da melhoria do estatus nutricional das plantas de Tifton 85. Esta influência do nitrogênio sobre a densidade populacional de perfilhos também foi relatado por Lemaire e Gastal (1997), e têm sido observado em cultivares de Panicum maximum (BARBOSA et al., 2002) e Brachiaria decumbens (FAGUNDES et al., 2006b).

Figura 3. Densidade populacional de perfilhos vegetativos, mortos e totais em pastos de capim Tifton 85 em função de doses de nitrogênio. *Significativo a 5\% pelo teste de Tukey.

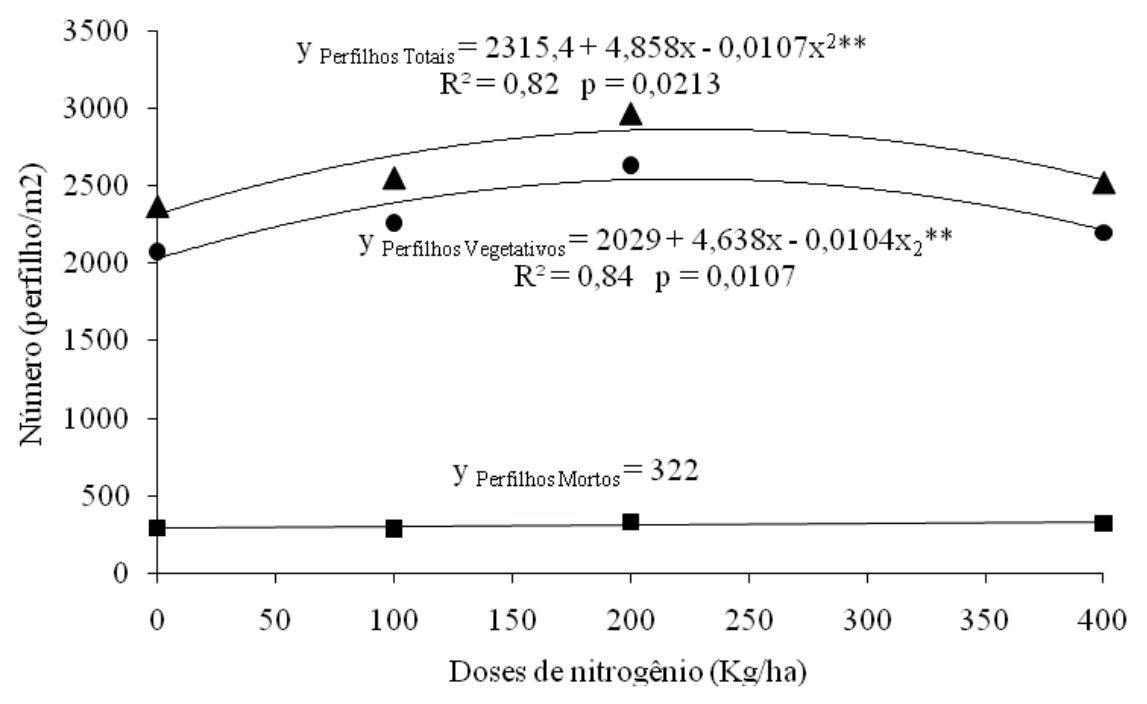

Fonte: Elaboração dos autores.

Cabe salientar que o efeito da adubação com $\mathrm{N}$ juntamente com o de períodos de avaliação sobre a população de perfilhos podem ser um dos principais fatores determinante da produção de biomassa juntamente com o rendimento por perfilho (NELSON; ASAY; SLEPER, 1977). 
Como a densidade de perfilhos em relvados pastejados é resultado do equilíbrio dinâmico entre taxa de aparecimento e morte de perfilhos provavelmente o IAF ótimo alcançado nas pastagens de Tifton 85 mantidas a $15 \mathrm{~cm}$ de altura decorreu do resultado da densidade de perfilhos que foi influenciada pelas doses de nitrogênio. Conforme demonstrado por Mazzanti e Lemaire (1994), o aumento na densidade de perfilho é o principal processo pelo qual a produção de forragem é incrementada pela adubação de $\mathrm{N}$ em pastos sob lotação contínua, pois a taxa de alongamento foliar em nível de perfilho individual não responde muito a nutrição de nitrogênio nessas condições. Assim sendo, manipulação da dinâmica do perfilhamento pode ser uma importante estratégia para o manejo de pastagem, principalmente porque a densidade populacional de perfilhos é determinante na perenidade do pasto (LEMAIRE; CHAPMAN, 1996).

A taxa de acúmulo de forragem (TAcF) de Tifton 85 respondeu de forma quadrática às doses de nitrogênio em dezembro, janeiro, fevereiro, março e abril (Figura 4). Este efeito diferencial entre as taxas de acúmulo em relação à época pode ser atribuído aos fatores climáticos (Tabela 1) que influenciaram na fenologia das plantas alterando as taxas de crescimento das mesmas. A resposta quadrática pode ser atribuída ao incremento da disponibilidade de nitrogênio no solo, proveniente da mineralização da matéria orgânica nas épocas avaliadas, pois, em geral, pastos mantidos sob mesma intensidade de pastejo e maiores doses de nitrogênio, tendem a apresentar maiores taxas de acúmulo de MS, conforme a estação do ano (FAGUNDES et al., 2005).

Pode-se notar um incremento na taxa de acúmulo com aplicação de nitrogênio (Figura 4), indicando que o suprimento de nitrogênio do solo normalmente não atende à demanda das gramíneas. Esse incremento em produção de forragem, proporcional às doses de nitrogênio em Tifton 85 , seguiu o mesmo padrão de resposta descrita por Paciullo, Gomide e Ribeiro (1998) e Fagundes et al. (2005, 2006a, 2006b). Esse efeito do nitrogênio pode ser atribuído à sua grande influência sobre os processos fisiológicos da planta (HERRERA; HERNANDEZ, 1985).

Figura 4. Taxa de acumulo de forragem em pastos de Tifton 85 submetidos a adubação nitrogenada. *Significativo a $5 \%$ pelo teste de Tukey.

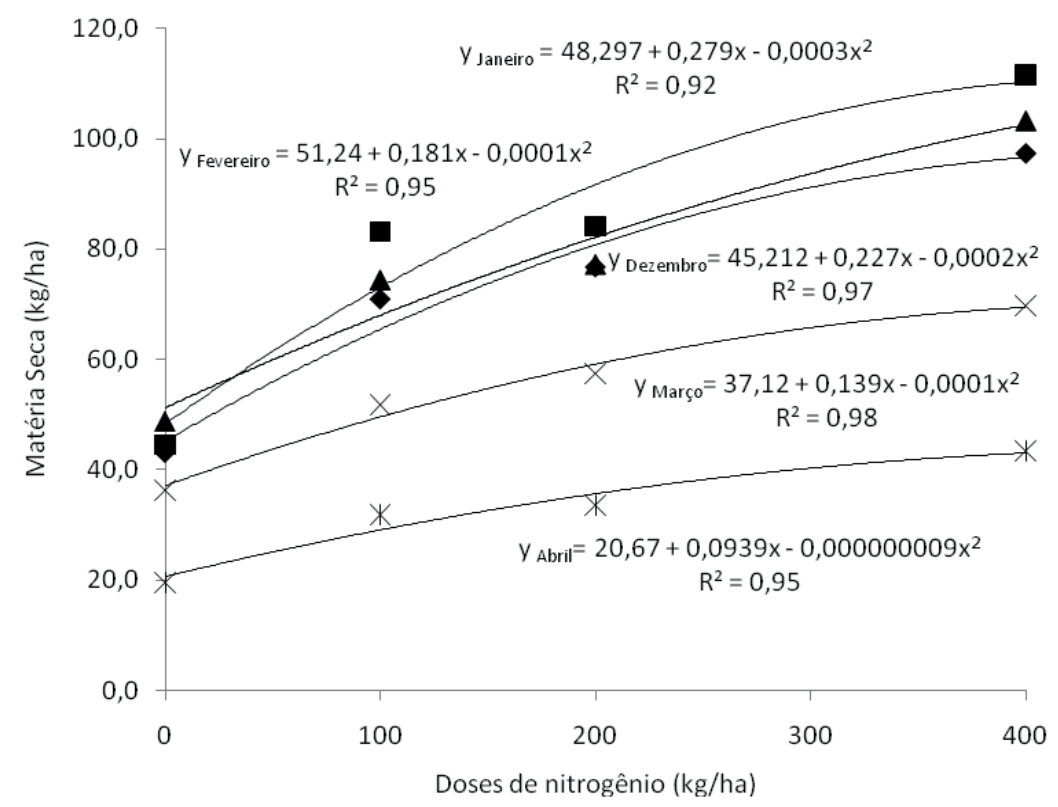

Fonte: Elaboração dos autores. 
Observou-se que as maiores TAcF ocorreram no mês de dezembro, janeiro e fevereiro e nas maiores doses de nitrogênio decaindo em março e abril (Figura 5), provavelmente como consequência dos baixos índices pluviométricos ocorridos (Tabela 1). Os valores mínimos de TAcF em março e abril, em razão a ocorrência de fatores inadequados de crescimento e, ou, desenvolvimento (água, luz e temperatura) típica daqueles meses do ano.

Figura 5. Taxa de acumulo de capim Tifton 85 submetidos a adubação nitrogenada avaliado em diferentes épocas do ano. *Significativo a $5 \%$ pelo teste de Tukey.

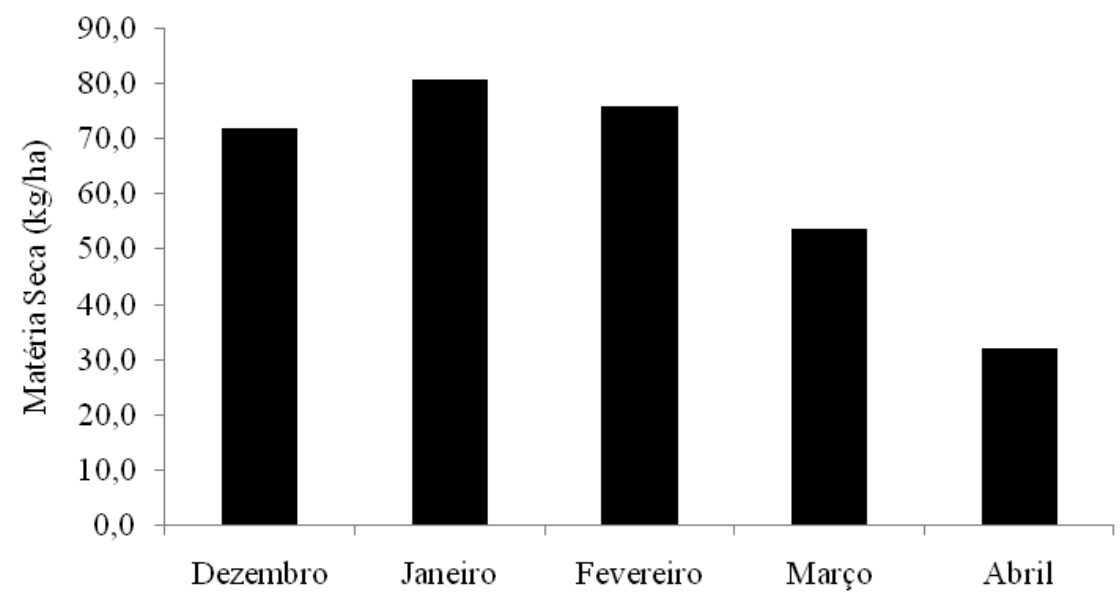

Epoca do ano

Fonte: Elaboração dos autores.

A constatação da interação época de avaliação e adubação nitrogenada na taxa de acúmulo de forragem do Tifton 85 pode ser devido ao efeito diferencial da época de avaliação e das doses de nitrogênio sobre as taxas de acúmulo do Tifton 85 também reflete a ação dos fatores climáticos e da adubação, que também influenciaram o IAF, IL e na densidade populacional de perfilhos, alterando as taxas de acúmulo de forragem.

A redução na TAcF observadas a partir do outono (março e abril) são decorrentes do início do período seco, no qual a ocorrência de condições adversas levam a diminuição da emissão de novas folhas, cessamento da alongamento e expansão das folhas podendo inibir, ainda, reduzir e, impedir o aparecimento de novos perfilhos, o que levaria a uma subsequente redução na produção do pasto (FAGUNDES et al., 2006a, 2006b). Assim, a biomassa de folha e de colmo nos diferentes tratamentos pode ser explicada pela taxa de aparecimento de folhas aliada à taxa de alongamento de folhas por perfilho e pela densidade populacional de perfilhos, pois os padrões de modificação dessas variáveis são determinantes dos rendimentos das forragens.

Os pastos de Cynodon cv. Tifton 85 foram influenciados pela época de avaliação e das doses de nitrogênio com efeito marcante na composição morfológica do pasto, índice de área foliar, interceptação luminosa e densidade de perfilhos que são determinantes no acúmulo de forragem. O cultivar Tifton 85 alcança condições necessárias para atingir a taxa de crescimento da cultura quando manejado sob lotação continua mantendo-se o pasto a $15 \mathrm{~cm}$ de altura uma vez que os menores valores de interceptação luminosa foram superiores a 95\%. Estudos com dosagens mais altas de nitrogênio são necessárias para medir o potencial máximo da cultura. 


\section{Referências}

BARBOSA, R. A.; NASCIMENTO JÚNIOR, D.; EUCLIDES, V. P. B.; REGAZZI, A. J.; FONSECA, D. M. Características morfogênicas e acúmulo de forragem do capim-tanzânia (Panicum maximum Jacq. cv. Tanzânia) em dois resíduos forrageiros pós-pastejo. Revista Brasileira de Zootecnia, Viçosa, MG, v. 31, n. 2 , p. 583-593, 2002.

BRASIL. Ministério da Agricultura. Serviço Nacional de Pesquisas Agronômicas. Comissão de Solos. Levantamento de reconhecimento dos solos do Estado de São Paulo. Rio de Janeiro, 1960. 634 p. (Boletim, 12).

CARNEVALLI, R. A.; DA SILVA, S. C. Validação de técnicas experimentais para avaliação de características agronômicas e ecológicas de pastagens de Cynodon dactylon cv. Coastcross-1. Scientia Agricola, Piracicaba, v. 56, n. 2, p. 489-499, 1999.

CARVALHO, C. A. B.; SILVA, S. C.; CARNEVALLI, R. A.; SBRISSIA, A. F.; PINTO, L. F. M.; FAGUNDES, J. L.; PEDREIRA, C. G. S. Perfilhamento e acúmulo de forragem em pastagens de Florakirk (Cynodon spp.) sob pastejo. Boletim de Industria Animal, Nova Odessa, v. 57, n. 1, p. 39-51, 2000.

DA SILVA, S. C.; CORSI, M. Manejo do pastejo. In: SIMPÓSIO SOBRE MANEJO DE PASTAGENS, 20., 2003, Piracicaba. Anais... Piracicaba: FEALQ, 2003. p. 155-186.

DA SILVA, S. C. Understanding the dynamics of herbage accumulation in tropical grass species: the basis for planning efficient grazing management practices. In: SYMPOSIUM ON GRASSLAND ECOPHYSIOLOGY AND GRAZING ECOLOGY, 2., 2004, Curitiba. Anais... Curitiba: UFPR, 2004. CD-ROM.

DAVIES, A. Tissue turnover in the sward. In: DAVIS, A; BAKER, R. D.; GRANT, S. A.; LAIDLAW, A. S. (Ed.) Sward measurement handbook. The British Grassland Society: University of Reading. 1993. p. 183-216.

DIFANTE, G. S.; NASCIMENTO JUNIOR, D.; SILVA, S. C.; EUCLIDES, V. B. P.; ZANINE, A. M.; ADESE, B. Dinâmica do perfilhamento do capim-marandu cultivado em duas alturas e três intervalos de corte. Revista Brasileira de Zootecnia, Viçosa, MG, v. 37, n. 1, p. 189196, 2008.

EMPRESA BRASILEIRA DE PESQUISA AGROPECUÁRIA - EMBRAPA. Centro Nacional de Pesquisa de Solos. Sistema brasileiro de classificação de solos. Rio de Janeiro: Embrapa Produção de Informação, 2009. 412 p.
FAGUNDES, J. L.; SILVA, S. C.; PEDREIRA, C. G. S.; CARNEVAlli, R. A.; CARVAlho, C. A. B.; SBRISSIA, A. F.; PINTO, L. F. M. Intensidades de pastejo e a composição morfológica de pastos de Cynodon spp. Scientia Agricola, Piracicaba, v. 56, n. 4, p. 897-908, 1999.

FAGUNDES, J. L.; FONSECA, D. M.; GOMIDE, J. A.; NASCIMENTO JÚNIOR, D.; VITOR, C. M. T.; MORAIS, R. V.; MISTURA, C.; REIS, G. C.; MARTUSCELLO, J. A. Acúmulo de forragem em pastos de Brachiaria decumbens adubados com nitrogênio. Pesquisa Agropecuária Brasileira, Brasília, v. 40, n. 4, p. 397-403, 2005.

FAGUNDES, J. L.; FONSECA, D. M.; MISTURA, C.; MORAIS, R. V.; VITOR, C. M. T.; GOMIDE, J. A.; NASCIMENTO JÚNIOR, D.; CASAGRANDE, D. R.; COSTA, L. T. Características morfogênicas e estruturais do capim-braquiária em pastagem adubada com nitrogênio avaliada nas quatro estações do ano. Revista Brasileira de Zootecnia, Viçosa, MG, v. 35, n. 1, p. 2129, 2006a.

FAGUNDES, J. L.; FONSECA, D. M.; MORAIS, R. V.; MISTURA, C.; VITOR, C. M. T.; GOMIDE, J. A.; NASCIMENTO JÚNIOR, D.; SANTOS, M. E. R.; LAMBERTUCCI, D. M. Avaliação das características estruturais do capim-braquiária em pastagens adubadas com nitrogênio nas quatro estações do ano. Revista Brasileira de Zootecnia, Viçosa, MG, v. 35, n. 1, p. 3037, 2006b.

HERRERA, R. S.; HERNANDEZ, Y. Efecto de la fertilización nitrogenada en la calidad de Cynodon dactylon cv. Coastcross: 1- Rendimiento de matéria seca, proteína bruta y percentage de hojas. Pastos y Forrages, Perico, v. 8, n. 1, p. 227-237, 1985.

LEMAIRE, G.; CHAPMAN, D. F. Tissue flows in grazed plant communities. In: HODGSON, J.; ILLIUS, A. W. (Ed.). The ecology and management of grazing systems. Oxon: CAB International, 1996. p. 3-36.

LEMAIRE, G.; GASTAL, F. N. Uptake and distribution in plant canopies. In: LEMAIRE, G. (Ed.). Diagnosis of the nitrogen status in crops. Paris: INRA, 1997. p. 3-43.

LIMA, J. A.; VILELA, D. Formação e manejo de pastagem de Cynodon. In: VILELA, D.; RESENDE, J. C.; LIMA, J. (Ed.). Cynodon: Forrageiras que estão revolucionando a pecuária Brasileira. Juiz de Fora: Embrapa Gado de Leite, 2005. p. 59-77.

LITTELL, R. C.; PENDERGAST, J.; NATARAJAN, R. Modelling covariance structure in the analysis of repeated measures data. Statistics in Medicine, Chichester, v. 19, n. 3, p. 1793-1819, 2000. 
MATTHEW, C.; ASSUERO, S. G.; BLACK, C. K.; SACKVILLE HAMILTON, N. R. Tiller dynamics of grazed swards. In: SIMPÓSIO INTERNACIONAL GRASSLAND ECOPHYSIOLOGY AND GRAZING ECOLOGY, 1., 1999, Curitiba. Anais... Curitiba: UFPR, 1999. p. 109-133.

MAZZANTI, A.; LEMAIRE, G. Effect of nitrogen fertilization on herbage production of tall fescue continuously grazed by sheep. 2 - Consumption and herbage efficiency utilization. Grass and Forage Science, Reading, v. 49, n. 3, p. 352-359, 1994.
NELSON, C. J.; ASAY, K. H.; SLEPER, D. A. Mechanisms of canopy development of tall fescue genotypes. Crop Science, Madison, v. 17, n. 1, p. 449452, 1977.

PACIULLO, D. S. C.; GOMIDE, J. A.; RIBEIRO, K. G. Adubação nitrogenada do capim-elefante cv. Mott. 1. Rendimento forrageiro e características morfofisiológicas ao atingir 80 e $120 \mathrm{~cm}$ de altura. Revista Brasileira de Zootecnia, Viçosa, MG, v. 27, n. 6, p. 1069-1075, 1998.

STATISTICAL ANALYSIS SYSTEM INSTITUTE SAS. SAS INSTITUTE. SAS/STAT user's guide. Versão 6.4. Cary, 1990.846 p. 